\title{
Impact of malocclusion on oral health-related quality of life among schoolchildren
}

\section{Soraia Pimenta de Araújo GUIMARÃES(a) \\ Kelly Oliva JORGE(b) \\ Maria Jussara Fernandes FONTES(c) \\ Maria Letícia RAMOS-JORGE ${ }^{(a)}$ \\ Cíntia Tereza Pimenta ARAÚJO(a) \\ Efigênia Ferreira FERREIRA(d) \\ Camilo Aquino MELGAÇO(b) \\ Patrícia Maria ZARZAR ${ }^{(\mathrm{e})}$}

(a) Universidade Federal dos Vales do Jequitinhonha e Mucuri - UFVJM, School of Dentistry, Department of Pediatric Dentistry, Diamantina, MG, Brazil.

(b) Universidade Vale do Rio Verde, School of Dentistry, Department of Pediatric Dentistry, Belo Horizonte, MG, Brazil.

(c) Universidade Federal de Minas Gerais UFMG, School of Medicine, Program in Health Sciences, Belo Horizonte, MG Brazil.

(d) Universidade Federal de Minas Gerais UFMG, School of Dentistry, Department of Oral Public Health, Belo Horizonte, MG, Brazil.

(e) Universidade Federal de Minas Gerais UFMG, School of Dentistry, Department of Pediatric Dentistry and Orthodontics, Belo Horizonte, MG, Brazil.

Declaration of Interests: The authors certify that they have no commercial or associative interest that represents a conflict of interest in connection with the manuscript.

\section{Corresponding Author:}

Soraia Pimenta de A. Guimarães

E-mail: sopigui@yahoo.com.br

https://doi.org/10.1590/1807-3107bor-2018.vol32.0095

Submitted: November 15, 2017

Accepted for publication: June 27, 2018

Last revision: July 26, 2018

\begin{abstract}
The aim of the present study was to evaluate the prevalence and impact of malocclusion on oral health-related quality of life (OHRQoL) among schoolchildren aged 8 to 10 years and their parents in Diamantina, a town in the southeast of Brazil. A cross-sectional study was conducted with a sample of 390 randomly selected children who were subjected to a clinical oral examination. The Dental Aesthetic Index was used to diagnose malocclusion and the need for orthodontic treatment. The Child Perceptions Questionnaire (CPQ (8-10)) was used to evaluate the impact of malocclusion on OHRQoL. The children's parents answered the Brazilian Economic Criterion Questionnaire for the socioeconomic classification. Data analysis involved the nonparametric Kruskal-Wallis test and Spearman's correlation coefficients. The variables were grouped into a hierarchy of categories ranging from distal to proximal determinants. Poisson regression analysis with robust variance was performed at each level to correlate the total CPQ (8-10) score with the independent variables. The prevalence of malocclusion was $78.7 \%$. Crossbite remained significantly associated with a negative impact on OHRQoL (PR = 1.28; 95\%CI:1.17-1.39; $\mathrm{p}<0.001)$. The prevalence of malocclusion was high in the sample investigated and exerted a negative impact on OHRQoL.
\end{abstract}

Keywords: Quality of Life; Malocclusion; Students; Adolescent.

\section{Introduction}

Oral health-related quality of life (OHRQoL) is a multidimensional concept that deals with the impact of poor oral health or disease on the performance of activities of daily living, well-being and quality of life. ${ }^{1}$ The interest in evaluating OHRQoL has grown in recent years and has increasingly been the subject of many studies. ${ }^{2}$

Malocclusion is a craniofacial growth and development disorder that can lead to functional problems, with a consequent impact on dental esthetics and on psychosocial aspects of children's and adolescents' lives. ${ }^{3}$ Epidemiological studies indicate that the prevalence and severity of malocclusion are greater in the permanent dentition, with rates ranging from $10.0 \%$ to $90.0 \% ., 5$ Thus, most studies addressing the impact of malocclusion on quality of life have evaluated adolescents. ${ }^{6,7}$ However, malocclusion can also occur during the mixed dentition phase and affect a child's self-image. ${ }^{8}$ Children begin to show their feelings about their dental appearance early on. At the age of 8 years, 
children have similar criteria to adults with regard to self-perceived body image. Orthodontic intervention in the mixed dentition allows the prevention or arrest of incipient malocclusions, contributing to the harmonious growth of the basal bones and normal development of the occlusion, reducing the chances of serious disorders in the permanent dentition. In addition, it is important to understand that even at early ages, the negative impact of malocclusion may contribute towards the search for improvements in children's and adolescents' emotional and social aspects. ${ }^{3,78}$ Dissatisfaction with the alignment and appearance of one's teeth and missing teeth are factors that exert an influence on the self-perceived need for orthodontic treatment among Brazilian schoolchildren. ${ }^{9}$

Clinical variables and the evaluation of OHRQoL provide information on the different aspects of malocclusion and the indication of treatment should be multidisciplinary, with the involvement of preventive efforts and early treatment to avoid greater harm. ${ }^{10}$ Such information is also useful for the planning of oral health services by health authorities. ${ }^{11}$

The evaluation of the need for orthodontic treatment should also consider the child's age. However, there is a lack of studies addressing the impact of malocclusion on the mixed dentition phase. Thus, the aim of the present study was to determine the prevalence of malocclusion and its impact on OHRQoL among schoolchildren aged 8 to 10 years in Diamantina, a town in the southeast of Brazil.

\section{Methodology}

\section{Subjects, setting, period of recruitment, and eligibility criteria}

The study population was composed of children enrolled in public and private schools and of their parents/ caregivers in Diamantina, a town located in the north of the state of Minas Gerais, in 2013. For their inclusion in the study, children and their parents/caregivers needed to be literate and fluent in Portuguese. The exclusion criteria were cognitive disorders, craniofacial anomalies, and previous orthodontic treatment.

\section{Sample size calculation}

Diamantina has 10 public and three private schools that offer elementary education. All schools were invited to participate in the study. In 2013, 1,492 schoolchildren were aged 8 to 10 years and enrolled in those schools, according to the lists provided by the Regional Education Superintendence and the Local Department of Education.

The sample size was calculated using the proportion estimate, a prevalence rate of $50.0 \%$, a $5.0 \%$ maximum acceptable error, and a 95.0\% confidence interval in the estimate of the prevalence. The initial sample was determined to include 384 schoolchildren, to which $20.0 \%$ was added to compensate for possible dropouts. The final sample should have 461 schoolchildren. The randomization procedure involved simple random sampling using the lottery method for the selection of students in the classroom.

\section{Calibration exercise and pilot study}

The children were examined for malocclusion and dental caries by one examiner (G.P.S.) who had been previously subjected to training and calibration exercises based on the Dental Aesthetic Index (DAI) criteria for the determination of the presence and severity of malocclusion and dental caries using the decayed, missing, and filled teeth (DMFT and dmft) indices recommended by the World Health Organization (WHO). Training involved the examination of color slides to practice the diagnostic criteria. The results of the examinations were compared to the judgments of a dentist with wide experience in the diagnosis of caries and malocclusions. Interrater (between the examiner and an experienced dentist) and intrarater agreement was determined using kappa $(\mathrm{K})$ coefficients, with $\mathrm{K}=0.90$ and 0.98 for the DAI, respectively, and $\mathrm{K}=0.92$ and $\mathrm{K}=$ 0.98 for dental caries, respectively. Intrarater agreement was determined based on two intraoral examinations of 20 children with a 1-week interval between sessions.

A pilot study was conducted with 25 eight-to-tenyear-old children enrolled in a public school to test the methods and understanding of the questionnaires. The children in the pilot study were not included in the main sample. The results demonstrated that there was no need to change the proposed methodology.

\section{Clinical oral examination}

The clinical examinations were performed in compliance with national biosafety recommendations. 
All children were examined at school seated under good natural light with the aid of disposable tongue depressors and a mouth mirror. The Dental Aesthetic Index (DAI) criteria were used for the diagnosis of malocclusion in mixed dentition. This index contains 10 components arranged into three groups (dentition, space, and occlusion), which are recorded as either present or absent or are measured using a millimeter WHO probe. Thus, except for dentition status, some components of the DAI are characterized by codes, whereas others are measured in millimeters. A simple instrument made with stainless steel orthodontic wire proposed by Santos et al. ${ }^{12}$ attached to a silicone or rubber endodontic plugger was used to measure DAI components. The plugger attached to the orthodontic wire allowed the juxtaposition of the wire and the reading point of the component. Linear DAI components were measured this way. ${ }^{12}$ The measurements were performed with sterilized millimeter rulers. The linear measurements and DAI components were recorded on a chart and subsequently multiplied by their respective weights. The results were calculated using the DAI equation to obtain the total DAI score. The DAI provides four possible outcomes: normal occlusion or minor malocclusion, the treatment of which is unnecessary $(\mathrm{DAI} \leq 25)$; definite malocclusion, the treatment of which is elective (DAI = 26 to 30); severe malocclusion, the treatment of which is highly desirable (DAI = 31 to 35 ); and very severe/ handicapping malocclusion, the treatment of which is fundamental (DAI $\geq 36$ ). For statistical purposes, the DAI score was dichotomized in the present study as absent $(\mathrm{DAI} \leq 25)$ or present $(\mathrm{DAI} \geq 26)$ malocclusion. The criteria for the diagnosis of dental caries were based on WHO recommendations, using the decayed, missing, and filled teeth indices (DMFT and $\mathrm{dmft}$ ). ${ }^{13}$ The children were allocated to two groups: those without untreated dental caries $(\mathrm{D} / \mathrm{d}$ component $=0)$ and those with one or more untreated caries (D component $\geq 1$ ).

\section{Nonclinical oral examination}

The impact on OHRQoL was evaluated through an interview using the Brazilian version of the Child Perceptions Questionnaire $\left(\mathrm{CPQ}_{8-10}\right)$, which was validated by Martins et al. ${ }^{14}$ This questionnaire contains 25 items distributed into four subscales: oral symptoms (five items), functional limitation (five items), emotional well-being (five items), and social well-being ( 10 items). The items address the frequency of events in the 4 weeks prior to the interview. There are five response options: never $=0$; once or twice $=1$; sometimes $=2$; often $=3$; and every day or almost every day $=4$. The total score is calculated by summing the item scores and ranges from 0 to 100, with higher scores denoting a greater impact on quality of life. There are also two questions for patient identification (sex and age) and two global indicators for the evaluation of overall oral health by the children and the extent to which an orofacial condition affects general well-being.

Children's parents answered the Brazil Criterion Questionnaire designed by the Brazilian Association of Research Companies, ${ }^{15}$ which was sent through the children participating in the study. The responses were subsequently confirmed by the researcher through telephone contacts. This questionnaire has questions about socioeconomic status and constitutes a standardized scoring system as an efficient estimator of purchasing power, with the establishment of cutoff points for segmentation into eight different socioeconomic classes (A1, A2, B1, B2, C1, C2, D, and E). The questions assess whether respondents have color TV set, DVD players, radio, bathrooms, automobiles, housekeeping service, washing machine, refrigerator, and freezer in the household, and also assess the level of schooling of the household head. ${ }^{15}$ For statistical purposes, socioeconomic status was dichotomized as more economically privileged (classes A1, A2, B1, and B2) or economically underprivileged (classes $\mathrm{C} 1, \mathrm{C} 2$, D, and E).

\section{Variables}

Impact on OHRQoL represented by the total $\mathrm{CPQ}_{(8-}$ 10) Score was the dependent variable. Malocclusion, the need for orthodontic treatment, socioeconomic status, and type of school were the independent variables. Dental caries was included in the analysis as a possible confounding variable for the impact on OHRQoL.

\section{Statistical analysis}

Data analysis was performed with the Statistical Package for Social Sciences (SPSS for Windows, version 20.0, SPSS Inc., Chicago, Illinois, USA). Descriptive statistics were performed for the total $\mathrm{CPQ}_{(8-10)}$ and subscale scores as well as the total DAI score, type 
of malocclusion, and demographic/socioeconomic characteristics. The Kolmogorov-Smirnov test was used to check the normality of the data distribution. The nonparametric Kruskal-Wallis test was used and Spearman's correlation coefficients were calculated. The variables were grouped into a hierarchy of categories ranging from distal to proximal determinants. The categories were socioeconomic factors, sociodemographic factors, and clinical oral status (in that order). Poisson regression analysis with robust variance was performed to correlate the total $\mathrm{CPQ}_{(8-10)}$ with the independent variables. Variables were incorporated into the model based on their statistical significance $(p<0.20)$. Explanatory variables with a $p$ value $<0.05$ after the adjustment at the same and previous determinant levels were kept in the final model.

\section{Ethical considerations}

This study was approved by the Human Research Ethics Committee of the Federal University of Minas Gerais (process no. 329.019) and was conducted in compliance with the recommendations of the Declaration of Helsinki. Authorization was obtained from the selected schools to undertake the study. The participants and their parents/guardians signed an informed consent form.

\section{Results}

A total of 461 children aged 8 to t10 years were randomly selected from a population of 1,462 schoolchildren in this age range in Diamantina. Twenty were excluded for wearing an orthodontic/orthopedic appliance and 51 were excluded for not having a signed the informed consent form,. Thus, 390 children and their parents/caregivers participated in the study.

The proportions of ages 8,9 , and 10 years were $35.9 \%$ $(\mathrm{n}=140), 33.8 \%(\mathrm{n}=132)$, and 30.3\% $(\mathrm{n}=118)$, respectively, and $50.8 \%$ were boys $(n=198)$. A total of $68.5 \%(n=267)$ were enrolled in state-run public schools. With regard to socioeconomic status, $33.1 \%(n=129)$ of the families were classified as economically underprivileged. A total of $29.5 \%(n=115)$ of the household heads had completed the fourth grade of elementary school and $28.7 \%(n=112)$ had a complete high school education.
A total of $38.2 \%$ ( $n=149)$ of the children were caries-free and the prevalence of malocclusion was $78.7 \%$.

Table 1 displays the distribution of the participants according to the DAI components, the need for orthodontic treatment, and dentition status.

Table 1. Distribution of sample according to type of malocclusion, treatment need, and dentition status $(n=390)$; Diamantina, Brazil, 2013.

\begin{tabular}{|c|c|c|}
\hline Variables & $\mathrm{N}$ & $\%$ \\
\hline \multicolumn{3}{|l|}{ Malocclusion } \\
\hline Absent & 83 & 21.3 \\
\hline Present & 307 & 78.7 \\
\hline \multicolumn{3}{|l|}{ Anterior crowding } \\
\hline None & 151 & 38.7 \\
\hline One or two segments & 239 & 61.3 \\
\hline \multicolumn{3}{|c|}{ Maxillary anterior crowding } \\
\hline$<2 \mathrm{~mm}$ & 313 & 80.3 \\
\hline$\geq 2 \mathrm{~mm}$ & 77 & 19.7 \\
\hline \multicolumn{3}{|c|}{ Mandibular anterior crowding } \\
\hline$<2 \mathrm{~mm}$ & 349 & 89.5 \\
\hline$\geq 2 \mathrm{~mm}$ & 41 & 10.5 \\
\hline \multicolumn{3}{|l|}{ Overjet } \\
\hline$<4 \mathrm{~mm}$ & 329 & 84.4 \\
\hline$\geq 4 \mathrm{~mm}$ & 61 & 15.6 \\
\hline \multicolumn{3}{|c|}{ Spacing in anterior segment } \\
\hline None & 215 & 55.1 \\
\hline One or two segments & 175 & 44.9 \\
\hline \multicolumn{3}{|l|}{ Incisor diastema } \\
\hline$<2 \mathrm{~mm}$ & 376 & 96.4 \\
\hline$\geq 2 \mathrm{~mm}$ & 14 & 3.6 \\
\hline \multicolumn{3}{|c|}{ Missing teeth (maxillary arch) } \\
\hline None & 375 & 96.2 \\
\hline One or two segments & 15 & 3.8 \\
\hline \multicolumn{3}{|c|}{ Missing teeth (mandibular arch) } \\
\hline None & 369 & 94.6 \\
\hline One or two segments & 21 & 5.4 \\
\hline \multicolumn{3}{|l|}{ Anterior open bite } \\
\hline$<2 \mathrm{~mm}$ & 378 & 96.9 \\
\hline$\geq 2 \mathrm{~mm}$ & 12 & 3.1 \\
\hline \multicolumn{3}{|l|}{ Anterior crossbite } \\
\hline Absent & 389 & 99.7 \\
\hline Present & 1 & 0.3 \\
\hline \multicolumn{3}{|c|}{ Orthodontic treatment need } \\
\hline None & 88 & 22.6 \\
\hline Elective & 111 & 28.5 \\
\hline Highly desirable & 98 & 25.1 \\
\hline Fundamental & 93 & 23.8 \\
\hline
\end{tabular}


No significant association was found between malocclusion and the impact on quality of life when the median values of the DAI and each subscale of the $\mathrm{CPQ}_{(8-10)}$ (Table 2) were accounted for.

Significant associations were found between the oral symptoms subscale and both the presence of anterior diastema and total DAI score as well as between mandibular anterior misalignment and both the total $\mathrm{CPQ}_{(8-10)}$ and functional limitation subscale (Table 3). Regarding sociodemographic variables, both type of school and socioeconomic status were significantly associated with OHRQoL. The occurrence of mandibular anterior crowding, anterior crossbite, and dental caries significantly increased the negative impact on OHRQoL (Table 4).

Table 2. Median values for DAl and $C P Q_{(8-10)}$ total and subscale $(n=390)$ scores; Diamantina, Brazil, 2013.

\begin{tabular}{|c|c|c|c|c|c|}
\hline \multirow{4}{*}{ Variable } & \multicolumn{4}{|c|}{ Dental Aesthetic Index } & \multirow{4}{*}{$p$-value* } \\
\hline & Grade 1 & Grade 2 & Grade 3 & Grade 4 & \\
\hline & $(<25)$ & $(26-30)$ & $(31-35)$ & $(>36)$ & \\
\hline & $88(22.6 \%)$ & 111 (28.5\%) & $98(25.1 \%)$ & $93(23.8 \%)$ & \\
\hline Oral symptoms & $5(0.19)$ & $5(0.18)$ & $6(0.20)$ & $6(0.19)$ & 0.189 \\
\hline Functional limitation & $2(0.19)$ & $3(0.16)$ & $4(0.20)$ & $4(0.20)$ & 0.424 \\
\hline Emotional well-being & $2(0.20)$ & $2(0.21)$ & $4(0.20)$ & $4(0.20)$ & 0.160 \\
\hline Social well-being & $2(0.36)$ & $2(0.28)$ & $3(0.40)$ & $3(0.28)$ & 0.346 \\
\hline Total CPQ & $12.5(0.92)$ & $12(0.78)$ & $19(0.100)$ & $17(0.67)$ & 0.212 \\
\hline
\end{tabular}

Data expressed as standard deviation in parentheses; * $\mathrm{p}$-value determined by the Kruskal-Wallis test.

Table 3. Impact on oral health-related quality of life (CPQ (8-10)) according to DAI variables ( $\mathrm{n}=390)$; Diamantina, Brazil, 2013.

\begin{tabular}{|c|c|c|c|c|c|c|}
\hline \multirow{3}{*}{ Independent variables } & \multicolumn{6}{|c|}{ Dependent variable $\left(C P Q_{(8-10)}\right.$} \\
\hline & & Total & \multirow{2}{*}{$\begin{array}{l}\text { Oral symptoms } \\
\text { score }\end{array}$} & \multirow{2}{*}{$\begin{array}{c}\text { Functional } \\
\text { limitation score }\end{array}$} & \multirow{2}{*}{$\begin{array}{l}\text { Emotional } \\
\text { well-being score }\end{array}$} & \multirow{2}{*}{$\begin{array}{l}\text { Social well-being } \\
\text { score }\end{array}$} \\
\hline & & $C P Q_{(8-10)}$ score & & & & \\
\hline \multirow[t]{2}{*}{ Incisor diastema (mm) } & r & -0.082 & -0.105 & -0.081 & -0.048 & -0.082 \\
\hline & $p$ & 0.105 & 0.038 & 0.111 & 0.343 & 0.106 \\
\hline \multirow[t]{2}{*}{ Maxillary anterior misalignment (mm) } & r & 0.006 & 0.018 & 0.001 & -0.001 & 0.020 \\
\hline & $\mathrm{p}$ & 0.911 & 0.719 & 0.988 & 0.985 & 0.688 \\
\hline \multirow[t]{2}{*}{ Mandibular anterior misalignment $(\mathrm{mm})$} & r & $0.100^{*}$ & 0.079 & $0.127^{*}$ & 0.069 & 0.064 \\
\hline & p & 0.047 & 0.120 & 0.012 & 0.173 & 0.210 \\
\hline \multirow[t]{2}{*}{ Maxillary anterior overjet $(\mathrm{mm})$} & r & 0.011 & 0.047 & -0.013 & 0.000 & 0.050 \\
\hline & $\mathrm{p}$ & 0.833 & 0.353 & 0.800 & 0.994 & 0.323 \\
\hline \multirow[t]{2}{*}{ Anterior crossbite $(\mathrm{mm})$} & r & 0.065 & 0.065 & 0.067 & 0.062 & 0.062 \\
\hline & $\mathrm{p}$ & 0.198 & 0.200 & 0.185 & 0.223 & 0.219 \\
\hline \multirow[t]{2}{*}{ Anterior vertical open bite (mm) } & r & 0.037 & 0.034 & 0.014 & 0.058 & 0.048 \\
\hline & $\mathrm{p}$ & 0.469 & 0.505 & 0.776 & 0.249 & 0.342 \\
\hline \multirow[t]{2}{*}{ Total DAI } & r & 0.090 & $0.107^{*}$ & 0.073 & 0.078 & 0.058 \\
\hline & $p$ & 0.075 & 0.034 & 0.148 & 0.124 & 0.252 \\
\hline
\end{tabular}

$r=$ Spearman's correlation coefficient $; p=$ significant if $<0.05$. 
Table 4. Impact on OHRQoL (CPQ $(8-10))$ independent variables ( $\mathrm{n}=390)$; Diamantina, Brazil, 2013.

\begin{tabular}{|c|c|c|}
\hline Independent variables & Prevalence ratio $(95 \% \mathrm{Cl})$ & p-value* \\
\hline \multicolumn{3}{|l|}{ Type of school } \\
\hline Private & $0.51(0.35-0.75)$ & $<0.001$ \\
\hline Municipal public & $1.16(0.96-1.41)$ & 0.134 \\
\hline State public & 1 & \\
\hline Socioeconomic status & & $<0.001$ \\
\hline Economically underprivileged ( $\mathrm{C} 1 / \mathrm{C} 2 / \mathrm{D} / \mathrm{E})$ & $1.44(1.20-1.73)$ & \\
\hline Economically more privileged (A1/A2/B1/B2) & 1 & \\
\hline Sex & & 0.241 \\
\hline Male & $0.90(0.75-1.07)$ & \\
\hline Female & 1 & \\
\hline \multicolumn{3}{|l|}{ Incisor diastema } \\
\hline$>2 \mathrm{~mm}$ & $0.97(0.59-1.61)$ & 0.912 \\
\hline$<2 \mathrm{~mm}$ & 1 & \\
\hline \multicolumn{3}{|l|}{ Mandibular anterior crowding } \\
\hline Present & $1.36(1.04-1.77)$ & 0.025 \\
\hline Absent & 1 & \\
\hline \multicolumn{3}{|l|}{ Anterior crossbite } \\
\hline Present & $2.14(1.05-2.34)$ & \\
\hline Absent & 1 & $<0.001$ \\
\hline \multicolumn{3}{|l|}{ Total DAl } \\
\hline With treatment need & $1.00(0.99-1.01)$ & 0.747 \\
\hline Without treatment need & 1 & \\
\hline \multicolumn{3}{|l|}{ Oral health } \\
\hline Presence of caries & $1.77(1.47-2.14)$ & $<0.001$ \\
\hline Absence of caries & 1 & \\
\hline
\end{tabular}

Anterior crossbite remained significantly associated with a negative impact on OHRQoL in the final hierarchical Poisson regression (Table 5).

\section{Discussion}

In the present study, malocclusion in the anterior segment was significantly associated with a negative impact on OHRQoL, which is in agreement with the data reported in previous studies. ${ }^{6,9,16}$ However, despite the fact that a child's self-perception of his/her appearance begins early on, Mtaya et al. ${ }^{16}$ state that those children are less concerned with malocclusion than dentists are. This hypothesis may explain the results found in a cross-sectional study with 1,601 students aged 12 to 14 years conducted in Tanzania, in which the majority of adolescents with normative orthodontic treatment needs reported no psychosocial impact related to their oral problems. Thus, the use of specific questionnaires for younger age groups is necessary; as such groups are homogeneous in terms of cognitive functions and skills.

The use of the $\mathrm{CPQ}_{(8-10)}$ allowed determining that schoolchildren aged 8 to 10 years are sensitive to the negative influence of malocclusion on dentofacial appearance (or the esthetic effect of malocclusion). Thus, schoolchildren with malocclusion, especially in the anterior region, may require orthodontic treatment to improve oral health, function, and esthetics, resulting in quality of life improvement. This is supported by the results of previous studies conducted with schoolchildren of similar age. ${ }^{6,17}$ 
Table 5. Hierarchical Poisson regression analysis of the impact on oral health related quality of life $\left(\mathrm{CPQ}_{(8-10)}\right)$ and independent variables $(n=390)$; Diamantina, Brazil, 2013

\begin{tabular}{|c|c|c|}
\hline Independent variables & $\begin{array}{c}\text { Prevalence ratio } \\
\quad(95 \% \mathrm{Cl})\end{array}$ & $p$-value* \\
\hline \multicolumn{3}{|l|}{ Type of school } \\
\hline Private & $0.62(0.42-0.92)$ & 0.018 \\
\hline Municipal public & $1.08(0.88-1.33)$ & 0.432 \\
\hline State public & 1 & \\
\hline \multicolumn{3}{|l|}{ Socioeconomic status } \\
\hline Economically underprivileged & $1.38(1.14-1.68)$ & 0.001 \\
\hline Economically more privileged & 1 & \\
\hline \multicolumn{3}{|l|}{ Anterior crossbite } \\
\hline Present & $1.44(1.27-1.65)$ & $<0.001$ \\
\hline Absent & 1 & \\
\hline \multicolumn{3}{|l|}{ Oral health } \\
\hline Presence of dental caries & $1.77(1.47-2.13)$ & $<0.001$ \\
\hline Absence of dental caries & 1 & \\
\hline \multicolumn{3}{|l|}{ Final model* } \\
\hline \multicolumn{3}{|l|}{ Type of school } \\
\hline Private & $0.73(0.54-0.98)$ & 0.034 \\
\hline Municipal public & 1.09 (0.89-1.33) & 0.411 \\
\hline State public & 1 & \\
\hline \multicolumn{3}{|l|}{ Socioeconomic status } \\
\hline Economically underprivileged & $1.25(1.03-1.51)$ & 0.022 \\
\hline Economically more privileged & 1 & \\
\hline \multicolumn{3}{|l|}{ Anterior crossbite } \\
\hline Present & $1.28(1.17-1.39)$ & $<0.001$ \\
\hline Absent & 1 & \\
\hline \multicolumn{3}{|l|}{ Oral health } \\
\hline Presence of dental caries & $1.67(1.38-2.01)$ & $<0.001$ \\
\hline Absence of dental caries & 1 & \\
\hline
\end{tabular}

*Controlled for sex.

Mixed dentition has peculiar characteristics when compared to permanent dentition. In some cases, the presence of habits or deviations in growth or in the development of occlusion may compromise the esthetics and function of individuals even at an early age. Thus, as the DAI was developed for permanent teeth, its use in mixed dentition could be oversensitive during this phase, possibly biasing the results due to transient developmental features. Also, the CPQ as a generic measure of OHRQoL could fail to address aspects specifically related to malocclusion. ${ }^{6}$
No association was found between sex and a negative impact on OHRQoL, which is in agreement with the data reported in previous studies. ${ }^{69,18}$ The result of the present study may also hypothetically be explained by the fact that children in the investigated age group perceived the psychosocial effect of malocclusion in a homogeneous fashion. ${ }^{9}$

The presence of malocclusion was associated with a negative impact on OHRQoL independently of the presence of dental caries or the socioeconomic status of the participants. Although some authors consider dental caries and premature primary tooth loss as predisposing factors for occlusal abnormalities in the mixed and permanent dentitions, ${ }^{19,20}$ the high prevalence of malocclusion in the present study may not be related to dental caries, but rather to functional habits that are unfavorable to the primary dentition related to the development of malocclusion inherent to the mixed dentition phase.

An association was found between malocclusion and economically underprivileged socioeconomic status, which may be explained by the difficulty in gaining access to orthodontic treatment and its high cost, as public healthcare services in Brazil do not offer orthodontic treatment, especially when such treatment is considered elective. ${ }^{6}$ In a study conducted in Brazil, Marques et al. ${ }^{9}$ found that $69.0 \%$ of individuals were unable to enjoy the benefits of orthodontic treatment due to the financial costs involved. This fact underscores the importance of investigations into both OHRQOL and malocclusion. When the evaluation of orthodontic treatment need is performed early on, better results are achieved in terms of self-esteem, esthetics, and function. ${ }^{21}$ Children who are still in the growth phase respond favorably to treatment in a shorter span of time, which requires fewer and more broad-scoped public resources.

The limitations of the present study are typical of the cross-sectional design, principally with regard to causal inference and information bias. It is also not possible to extrapolate the findings to the students who were absent on the day of the survey or those who do not attend schools in Diamantina. The results showed a low prevalence of anterior crossbite and this finding may be a characteristic of the specific population of the studied geographic region. Concerning the 
negative impact of malocclusion on the quality of life, it should be analyzed with caution, and it cannot be applied to the entire population in this age group.

The age group evaluated here may also be considered a limitation of the study, as the DAI was developed for the permanent teeth. When used in mixed dentition only small changes are accounted for by the index. Thus, there may be a tendency toward underestimating the results in the mixed dentition phase. Using the DAI as an isolated instrument to assess malocclusion and need for orthodontic treatment is controversial, since it can be complemented by other indices. ${ }^{6}$ Therefore, the exclusive use of DAI in this study was a limitation as well.

The results of the present study may affect clinical decisions concerning early orthodontic treatment. It is important to evaluate malocclusion among children in the mixed or initial permanent dentition phase, as an early diagnosis can guide preventive/interceptive orthodontic treatment, thereby taking advantage of the child's growth potential. Concerning the

\section{References}

1. Martins-Júnior PA, Marques LS, Ramos-Jorge ML. Malocclusion: social, functional and emotional influence on children. J Clin Pediatr Dent. 2012;37(1):103-8. https://doi.org/10.17796/jcpd.37.1.y75430328427210i

2. Ni Riordain R, McCreary C. The use of quality of life measures in oral medicine: a review of the literature. Oral Dis. $2010 \mathrm{Jul} ; 16$ (5):419-30. https://doi.org/10.1111/j.1601-0825.2009.01647.x

3. Masood Y, Masood M, Zainul NN, Araby NB, Hussain SF, Newton T. Impact of malocclusion on oral health related quality of life in young people. Health Qual Life Outcomes.2013;11:25. https://doi.org/10.1186/1477-7525-11-25

4. Silva RG, Kang DS. Prevalence of malocclusion among Latino adolescents. Am J Orthod Dentofacial Orthop. 2001 Mar;119(3):313-5. https://doi.org/10.1067/mod.2001.110985

5. Marques LS, Ramos-Jorge ML, Paiva SM, Pordeus IA. Malocclusion: esthetic impact and quality of life among Brazilian schoolchildren. Am J Orthod Dentofacial Orthop. 2006 Mar;129(3):424-7. https://doi.org/10.1016/j.ajodo.2005.11.003

6. Sardenberg F, Martins MT, Bendo CB, Pordeus IA, Paiva SM, Auad SM et al. Malocclusion and oral health-related quality of life in Brazilian school children. Angle Orthod. 2013 Jan;83(1):83-9. https://doi.org/10.2319/010912-20.1 subjective need for treatment perceived by children, it is also important to establish physical and emotional well-being in childhood and adolescence. Multicenter studies should be conducted to evaluate the impact of malocclusion on the OHRQoL of children and their families, ${ }^{22}$ obtaining data that can assist in the establishment of health policies directed at the inclusion of multidisciplinary treatment so that health procedures can be implemented and made accessible to the population.

\section{Conclusion}

The prevalence of malocclusion in the present study was high and was associated with a negative impact on OHRQoL among schoolchildren aged 8 to 10 years.

\section{Acknowledgments}

The authors wish to thank the Brazilian Council for Scientific and Technological Development (CNPq) for financial support.
7. Abreu LG, Melgaço CA, Abreu MH, Lages EM, Paiva SM. Effect of malocclusion among adolescents on family quality of life. Eur Arch Paediatr Dent. 2015 Aug;16(4):357-63. https://doi.org/10.1007/s40368-014-0172-6

8. Tausche E, Luck O, Harzer W. Prevalence of malocclusions in the early mixed dentition and orthodontic treatment need. Eur J Orthod. 2004 Jun;26(3):237-44 https://doi.org/10.1093/ejo/26.3.237

9. Marques LS, Ramos-Jorge ML, Ramos-Jorge J, Pereira IJ, Paiva SM, Pordeus IA. Self-perception regarding the need for orthodontic treatment among impoverished schoolchildren in Brazil. Eur J Paediatr Dent. 2009;10:125-30.

10. Lawrence HP, Thomson WM, Broadbent JM, Poulton R. Oral health-related quality of life in a birth cohort of 32-year olds. Community Dent Oral Epidemiol. 2008 Aug;36(4):305-16. https://doi.org/10.1111/j.1600-0528.2007.00395.x

11. Ferreira MC, Goursand D, Bendo CB, Ramos-Jorge ML, Pordeus IA, Paiva SM. Agreement between adolescents' and their mothers' reports of oral health-related quality of life. Braz Oral Res. 2012 Mar-Apr;26(2):112-8. https://doi.org/10.1590/S1806-83242012000200005 
12. Santos PC, Monteiro AL, Rodney GR. Chaves-Júnior CM. Uma ferramenta alternativa para avaliação do índice dental estético. Rev Clin Ortodon Dental Press. Maring. 2008;7:34-9.

13. World Health Organization - WHO. Oral health surveys: basic methods. 4th ed. Geneva: World Health Organization; 1997.

14. Martins MT, Ferreira FM, Oliveira AC, Paiva SM, Vale MP, Allison PJ et al. Preliminary validation of the Brazilian version of the child perceptions questionnaire 8-10. Eur J Paediatr Dent. 2009 Sep;10(3):135-40.

15. Associação Brasileira de Empresas de Pesquisa - ABEP. O novo critério padrão de Classificação Econômica Brasil. São Paulo: Associação Brasileira de Empresas de Pesquisa; 2012.

16. Mtaya M, Astrom AN, Brudvik P. Malocclusion, psycho-social impacts and treatment need: A cross-sectional study of Tanzanian primary school-children. BMC Oral Health. 2008 May;8(1):14. https://doi.org/10.1186/1472-6831-8-14

17. Dias PF, Gleiser R. Orthodontic concerns of Brazilian children and their parents compared to the normative treatment need. J Oral Sci. 2010 Mar;52(1):101-7. https://doi.org/10.2334/josnusd.52.101
18. Feldens CA, Nakamura EK, Tessarollo FR, Closs LQ. Desire for orthodontic treatment and associated factors among adolescents in Southern Brazil. Angle Orthod. 2015 Mar;85(2):224-32. https://doi.org/10.2319/021014-105.1

19. Frazão P, Narvai PC, Latorre MRDO, Castellanos RP. Prevalência de oclusopatia na dentição decídua e permanente de crianças na cidade de São Paulo, Brasil, 1996. Cad Saúde Pública. 2002;18(5):1197-205. https://doi.org/10.1590/S0102-311X2002000500012

20. Mtaya M, Brudvik P, Astrøm AN. Prevalence of malocclusion and its relationship with socio-demographic factors, dental caries, and oral hygiene in 12- to 14 -year-old Tanzanian schoolchildren. Eur J Orthod. 2009 Oct;31(5):467-76. https://doi.org/10.1093/ejo/cjn125

21. Chen M, Feng ZC, Liu X, Li ZM, Cai B, Wang DW. Impact of malocclusion on oral health-related quality of life in young adults. Angle Orthod. 2015 Nov;85(6):986-91. https://doi.org/10.2319/101714-743.1

22. Abreu LG, Melgaço CA, Abreu MH, Lages EM, Paiva SM. Impact of the first eight months of orthodontic treatment with a fixed appliance on the families of adolescent patients. Angle Orthod. 2014 Nov;84(6):1074-8. https://doi.org/10.2319/011014-37.1 